\title{
The Conditions of the Environment as Factors Affecting the Social and Political Stability of Populations
}

\author{
Fausto Pedrazzini* \\ Consiglio Nazionale delle Ricerche / Istituto di Fisiologia Clinica \\ Via Trieste 41, 56125 Pisa, Italy
}

Received: 23 December 2009. Accepted: 26 May 2010.

\begin{abstract}
In this review article, the different conditions of the environment which could affect the well-being of the populations living on it are taken into consideration and analysed. A specific attention is paid to the phenomenon of water reduction, land degradation and consequent desertification. Such a phenomenon is particularly worrying in selected regions of the world (the Mediterranean Region and Central Asia) in which a combination of several factors including climate variations, pressure of populations and increased competition for the available resources have a direct consequence on the economical, social and political conditions of the population. In addition, migrations could also take place, increasing the instability of entire regions.

A proper management of water resources and the preservation of land and soil resources are essential requisites to counteract the mentioned adverse effects. Such a management is frequently a transboundary concern since it might involve different regions and countries; this is an additional reason for debating the environment degradation issues at the international level and for increasing the awareness of the civil society, the policy makers and governments.
\end{abstract}

Key-words: environment degradation, environmental resources, desertification, environmental security.

\section{Introduction}

The natural environment is the primary provider of essential resources like water, soil and vegetation, which are the basis for an equilibrate exploitation aimed at sustaining food and energy production. These resources normally exist in a natural equilibrium, which might be altered both, by man-made and by natural events.

The reduction of water resources, the land degradation and the desertification are the most common consequences of the disruption of natural equilibria and have direct negative consequences on the general status of the ecosystem and on the people who are living there.

The decrease of available resources, the competition to get access to them, the social and political instability and migration, are also conse- quences of a degraded environment and are directly related to the security of population.

Some regions of the world are more exposed than others to environmental threats (the Mediterranean basin; the Middle East; Central Asia, etc.) and on top of the limitation of natural resources, the existing political and cultural differences are often reasons for making more difficult the implementation of co-operative initiatives aimed at stabilising and possibly improving the conditions of the natural environment.

Natural and man induced disasters might worsen the status of vulnerable ecosystems and causing conditions which do not allow a sustainable development of populations. By consequence, massive and sudden movements of people occurs, thus affecting the stability of the con-

* Corresponding Author: Tel.: +39 050 3153706; Fax: +39 050 3153713. E-mail address: fausto.pedrazzini@ifc.cnr.it. 
cerned region. The degradation of the environment is unfortunately a self sustaining process, by which an abandoned territory is more and more fragile and degraded, since the basic practices for maintaining it are no longer enforced.

National plans are the first step to counter environmental degradation, however, an increased collaboration across political boundaries is needed to cope with adverse phenomena which affect broad geographical areas.

\section{Discussion}

Soil degradation, consisting in a generalised loss of its productive layer both in terms of quantity and quality, is driven by several factors including the abandon of traditional agricultural practices and a poor water management. This has as a consequence a deep degradation of the whole ecosystem, which in some specific situations and geographical areas could lead to a process (frequently irreversible) known as desertification.

According to statistics touted by the International Union of Soil Scientists, over the last 300 years the average soil loss was 200 million tons per year and in the past 50 years this average has reached 760 million tons. Six million hectare in annual loss to soil degradation is irreversible and it is estimated that about half of the desertified area worldwide requires rehabilitation. The cost of rehabilitation over a 20-year period has been calculated to be about $\$ 213$ billions; if not rehabilitated the income foregone in the same period will be $\$ 564$ billions (de Kalbermatten, 2009).

The concept of desertification has been deeply debated and analysed by specialists; however, the general definition issued by the United Nations Convention to Combat Desertification (UNCCD) is still the most accurate. It states that desertification is the soil degradation in an arid or sub-humid environment, which implies the reduction or the loss of the biological productivity of agricultural and irrigated land, as well as of pastures and forests. Such a concept has been strengthen afterwards by Adeel et al. (2005), by stating that what defines more specifically the desertification, is the "persistence" of such a phenomenon.

As a matter of fact, the fluctuations of the potential of an ecosystem to provide resources and essential services should be considered normal (particularly in arid or semi-arid regions), but is the persistent reduction of resources or services for a prolonged period which determines the development of desertification in a given environment (Safriel, 2009).

In December 2006 the United Nations University has published a study considering the desertification as one of the most important and actual menaces to the environment. Within the introduction of the book published on this subject, the following statement is written: "Desertification is nowadays one of the most important challenges for the global environment, because it is a phenomenon which might reduce and inhibit the sustainable development which had started to develop in different parts of the world. Such a process might destabilise the society by increasing the poverty and by creating the conditions for migrations induced by altered environmental conditions, beside inducing an increased pressure on those areas which are not degraded yet".

The phenomenon of desertification and the consequent competition for the residual resources have also a direct influence on the economic, social and political stability of the concerned populations and of the nations to which they belong. Particularly there are some regions of the world in which, besides the environmental vulnerability and the limitation of the available resources, there are also political and cultural differences which increase the tension and the potential for conflicts and also limit the possible collaborations aimed at stabilising and possibly improving the environmental conditions. This situation is more evident in regions like the Middle East and Central Asia. Therefore desertification is becoming more and more related to security issues in general and to environment security more specifically. In fact, the soil degradation and the reduction of its biological fertility have a negative effect on food production exposing populations to malnutrition and to diseases. The sad conclusion of this process is that when health and feeding are in danger, populations leave their homes and migrate in other regions; frequently in other countries, causing again ethnic tension and conflicts. It was established by a study of Brauch (2003) that even if only the $28 \%$ of the 485 conflicts which took place in the Mediterranean region in the peri- 
od 1975-2001 were originated by dryness and consequent food shortage, the same conflicts have involved 10,5 million people which is about the half of the 22 million people concerned by conflicts due to other reasons.

By virtue of its capacity to trigger famines, internal displacements and international migration, desertification often serves as a recipe for political instability (Algeria, Chad), for tension between neighbouring countries, and even for armed conflicts. It is not coincidental that in the Sahel zone of Africa, not a single government survived the droughts of the 1970s and 1980s. Desertification and drought threaten the livelihoods of one billion people in more than 110 countries, and another one billion are at risk. Yet according to the UNCCD, a 20-year global effort would cost no more than $\$ 22$ billions per year, with savings for agriculture alone worth $\$$ 42 per year (Myers, 2004).

A dramatic example of the interactions between land use and conflict is the Darfur conflict in which a combination of different factors including ecological risks; natural resources sufficient but neglected \& undeveloped; marginalisation; bad governance and ethnic conflicts, gave origin to civil war and genocide (Ibrahim, 2007). On June 2007, the UN Secretary general made on this some very relevant comments. He said: "The Darfur conflict began as an ecological crisis, arising at least in part from climate change [...] It is no accident that the violence in Darfur erupted during the drought [...] When Darfur's land was rich, black farmers welcomed Arab herders and shared their water [...] For the firs time in memory, there was no longer enough food and water for all. Fighting broke out".

If the environmental degradation is a factor of social instability which could facilitate the development of conflicts between populations and countries, it should also be considered that unfortunately the inverse phenomenon could also occur, meaning that an ethnic or political conflict causes enormous damages to the populations, but even to the environment of the territories where the conflict takes place.

Environment degradation is unfortunately a self-sustaining process: as a matter of fact if a territory is abandoned by the populations which live there, the same territory will become even more degraded and fragile, because the agricultural practices and water management needed to maintain the fertility, will no longer enforced (Pedrazzini, 2008).

In addition to the risks of land degradation and desertification, natural or man-induced environment disasters, could worsen the environmental conditions of particularly fragile regions, causing damages which will reduce the opportunity of the populations to live there. Among the natural disasters the forest fires should be included. These are one of the most frequent causes of desertification. Unfortunately their occurrence is dramatically increasing, as happened recently in many regions of the world (California, Australia, Greece, Portugal etc.). It is foreseeable that the the global warming tendency and the possible increased aridity of several regions could imply increased danger of forest fires. In the Mediterranean region, a close relationship between forest fires and aridity has been historically proven. This should be taken as a warning (Rubio, 2009).

Planning a proper land and environment management in a specific country is something which should be implemented as early as possible to avoid an irreversible environmental degradation. It is also necessary to develop international collaborations, since the environment degradation phenomena do no respect political borders, on the contrary they frequently concern regions which include different countries. On this issue, international organisations could play an important role and become platforms for trans-national collaborations, aimed at evaluating to what degree the not proper management of land agricultural resources could affect the life conditions; the stability and ultimately the security of the populations living in a specific region (Pedrazzini and Daussa, 2009).

Several international organisations, including UNDP, UNEP, OSCE and NATO launched a few years ago a cooperative partnership called ENVSEC initiative aimed at addressing environmental risks to security and at fostering stability through environmental cooperation.

ENVSEC is a programme set up to assess links between environment and security in a number of regions including Central Asia, Southern Caucasus, the Balkans and Eastern Europe. The methods used by ENVSEC is to conduct regional assessments by a collection of experts including regional experts. These assessments result afterwards in a desk study 
which forms the basis for regional initiatives like creating regional maps highlighting issues and areas where environmental problems influence security or are a possible source for transboundary environmental cooperation (Borthwick, 2009).

The same international organisations promoted and organised in these last years, meetings and workshops aimed at identifying the security issues related to the environmental degradation, particularly in the Mediterranean area.

The Mediterranean basin is actually one of the five regions of the globe characterised by the Mediterranean climate: a long and dry hot season and consequently low but intense precipitations in the rest of the year. The regions with this kind of climate are classified as dry or semi-arid. Compared to the other regions with the same climate, the Mediterranean basin has been for a longer period extensively exploited by populations, with a continuous pressure on the available resources, causing a more significant land degradation (Safriel, 2009).

The Region has a rich experience of conflicts and convergences, of cohabitation between pastoralist societies and sedentary structures, Islam and Christianity, diverging views or accommodating differences. In half a century its population will almost double from 285 million inhabitants in 1970 to 544 million around 2020. But if population stabilises on the Northern shores, it explodes on the Southern one, with a population of 116 million in 1970 jumping to 331 million in 2020 (de Kalbermatten, 2009).

In the Mediterranean rim countries, water resources are limited and very unequally distributed over space and time. Southern rim countries receive only $10 \%$ of the total precipitation. Twenty million Mediterranean people do not have access to drinking water, particularly in the South and the East. By 2025, the water-poor population - with less than $1.000 \mathrm{~m}^{3}$ per capita per year - could increase to 250 million (Thibault, 2009).

Assuming that there will be an increased demographic pressure in the Mediterranean region, associated with the tendency to climate change, there will be an increased risk of land degradation associated with an intensification of the phenomenon of desertification. This will have a negative consequence on the well being of the populations living in the considered area and the economically and socially weaker countries will be even more affected. Thus the impact of desertification on these countries could become a potential threat towards their stability.

To tackle this issue, a workshop has been organised at the end of 2007 in Valencia (Spain) by NATO (Science for Peace and Security Programme) and by the OSCE a workshop on "Water Scarcity, Land Degradation and Desertification in the Mediterranean Region - Environmental and Security Aspects" and the following recommendations were put forward:

- even though there is a consolidated knowledge on the biophysical factors which influence the desertification in the Mediterranean region, it is necessary to deepen the analysis and the evaluation of the social, economical and political consequences of such a phenomenon;

- a better understanding of the potential effect of climate change on the ecological, economical and social conditions of the Mediterranean region is necessary, along with a specific attention to water resources;

- it was considered essential to put into practice sensing and signaling methods \& technologies to prevent and counter extreme events like dryness and forest fires, for which an intensification in the Mediterranean region is expected;

- procedures to prevent desertification should be planned and implemented, even for mitigating the possible effects of climate change;

- initiatives concerning the reduction of the impact of increasing population on water resources and on soil fertility should also be taken into consideration;

- the concept of Environment Security should be better defined. As a matter of fact, the scientific community and the politicians do not always have the same perception on this. Consequently more specific analysis should be made, by taking into consideration those specific cases in which the environmental degradation an the desertification have shown to be the determining factors in relation with the loss of stability and security by populations.

The recommendations and the concepts elaborated at the meeting in Valencia have been brought to the attention of the representatives of the NATO and OSCE member countries and 
have been taken into account by delegates of the UNCCD. The debate which developed on that occasion, should be taken as a contribution towards elaborating a wider concept of security which should also imply the preservation of the environment and of its resources for the benefit of populations. This is an issue that, even if stemming from local concern, cannot avoid the international collaboration in view of elaborating successful strategies.

\section{References}

Adeel Z., Safriel U. et al. 2005. Ecosystems and Human Well being Desertification Synthesis. Millennium Ecosystem Assessment, World Resource Institute, Washington, DC.

Borthwick F. 2009. International Organisations Cooperation around Environment and Security. In: Stec S., Baraj B. (eds.): Energy and Environmental Challenges to Security. Springer Science and Business Media.

Brauch H.G., Liotta P.H. et al. 2003. Security and Environment in the Mediterranean. Conceptualising Security and Environmental Conflicts. Springer, Berlin.

de Kalbermatten G. 2009. Grounding Security, Securing the Ground. In: Rubio J.L., Safriel U. et al. (eds.): Water Scarcity, Land Degradation and Desertification in the Mediterranean Region. Springer Science and Business Media.

Ibrahim F.N. 2007. Interactions between Land Use an Conflicts: the Darfur Conflict. In: Desertification: a Security Threat? Berlin, June 26, 2007. Available at: www.gtz.de.

Myers N. 2004. Environmental Security: What's new and different? Background paper for The Hague conference on Environment, Security and Sustainable Environment.

Pedrazzini F. 2008. Water Scarcity, land Degradation and Desertification as Factors for Social and Political Instability. In: Environment, Forced Migration \& Social Vulnerability, International Conference Proceedings. www.efmsv2008.org.
Pedrazzini F., Daussa R. 2009. Introduction. In: Rubio J.L., Safriel U. et al. (eds.): Water Scarcity, land degradation and Desertification in the Mediterranean Region. Springer Science and Business Media.

Rubio J.L. 2009. Desertification and Water Scarcity as a Security Challenge in the Mediterranean. In: Rubio J.L., Safriel U. et al. (eds.): Water Scarcity, Land Degradation and Desertification in the Mediterranean Region. Springer Science and Business Media.

Safriel U. 2009. Status of Desertification in the Mediterranean Region. In: Rubio J.L. Safriel U. et al. (eds.): Water Scarcity, Land Degradation and Desertification in the Mediterranean Region. Springer Science and Businness Media.

Thibault H.-L. 2009. Facing Water Crisis and Shortages in the Mediterranean. In Rubio J.L. Safriel U. et al. (eds.): Water Scarcity, Land Degradation and Desertification in the Mediterranean Region. Springer Science amd Business Media.

\section{Documents analysed}

Civil Emergency Planning. A key Security Task for the Alliance. Available at http://www.nato.int/issues/cep/ index.html.

NATO Science for Peace and Security Programme. Available at http://www.nato.int/science.

Millennium Ecosystem Assessment, 2005. Ecosystems and Human Well Being \& Desertification Synthesis. World Resources Institute, Washington, DC.

Desertification: a Security Threat? Analysis of risks and challenges. A Conference on the occasion of the World Day to Combat Desertification. Berlin, June 26, 2007. Available at: http://www.gtz.de.

The United Nations University-Institute for Environment and Human Security UNU-EHS. Homepage http://www.ehs.unu.edu/.

ENVSEC Environment and Security Initiative. Homepage http://www.envsec.org/.

UNCCD Homepage http://www.unccd.int.

Institute for Environmental Security. Homepage http:// www.envirosecurity.org.

United Nations Environment Programme UNEP. Homepage http://www.unep.org. 